\title{
Research on the Marketization of Urban and Rural Factors and the Coordinated Development of Urban and Rural Industries and Regions
}

\author{
Bin Huang ${ }^{1}$, Xiaoxi Liao ${ }^{2 *}$ \\ ${ }^{1}$ Business School of Lishui University, Lishui, 323000 China \\ ${ }^{2}$ Hubei Construction Engineering Group Co., Ltd. 430071 China \\ *Corresponding Author.
}

\begin{abstract}
At present, China is facing the problem of breaking down the system and institutional obstacles that hinder the free flow of factors. The development of new urbanization and urban and rural industries depends on the independent flow, efficient and fair allocation of factor markets; market-oriented allocation of factors is the development and core issue of new urbanization; the market plays a decisive role in the allocation of factor resources. On this basis, it is of great importance to put forward suggestions to further promote the free flow of factors and accelerate the development of new urbanization.
\end{abstract}

Keywords: Factors allocation; marketization of urban and rural factors; new urbanization; urban-rural coordinated development, Urban and Rural Industries

\section{Introduction}

The new urbanization has the characteristics of urban and rural coordination, urban and rural integration, industrial interaction, economic intensive, ecological livability, and harmonious development. The urban and rural elements are rationally allocated, coordinated and developed, and promote each other. Large, medium and small cities, small towns and new rural communities. December 29, 2014, China integrated pilot officially announced the list of new urbanization. [1] The report emphasizes the big party nineteenth establish and improve the urban and rural integrated development of institutional mechanisms and policy system in the implementation of rural revitalization strategy. [2] April 8, 2019, the National Development and Reform Commission issued "2019 new urbanization construction of key tasks," and proposed to deepen the reform of the household registration system, the task of promoting the coordinated development of medium-sized cities. It has important and positive significance for optimizing the layout and form of my country's urbanization and promoting the high-quality development of new urbanization. On May 22, 2020, Premier Li Keqiang of the State Council of China put forward in the 2020 Government Work Report of the State Council that the construction of new urbanization should be strengthened, and the public facilities and service capacity of county towns should be greatly improved to meet the increasing demand of farmers for employment and settlement in county towns. The new type of urbanization should be further promoted. Central cities and urban agglomerations should play a leading role in fostering industries and increasing employment. The position that houses are used for living, not for speculation, should be adhered to and measures should be taken according to different conditions in the cities to promote the steady and healthy development of the real estate market. Convenience facilities should be improved to make the city more pleasant and livable. [3] New urbanization is a strong support to promote the coordinated development of China's region, an important way to solve the problems of China's agriculture, rural areas and peasants, and a powerful engine to promote high-quality economic development. Urbanization in China is constantly pushing forward the further development of high-density urban areas and the strengthening of urban infrastructure and public services. [1] In 2021, in the Government Work Report of the Two Sessions of CPC, it was proposed to "push forward the new urbanization in depth" and incorporate the new urbanization construction into the "new infrastructure and new urbanization initiatives and major projects" construction (new infrastructure construction, new urbanization

ISSN: 0010-8189 
construction, transportation, water conservancy and other major projects). [4] The Key Tasks for the Construction of New Urbanization and the Development of Urban-Rural Integration in 2020, promulgated by the National Development and Reform Commission of China on April 9, covers urban rail transit, renovation, environmental protection and clean energy, water conservancy facilities, pipelines for oil and gas transmission, medical treatment, education, cultural style, and old-age facilities. Thus it is clear that market-based allocation of factors is particularly important to promote the development of new urbanization. The key to promote new urbanization is market-based factors. Urbanization in China is speeding up the flow of urban and rural factors, the marketization of factors and the redistribution of resources throughout the society, which will ultimately affect the coordinated development of urban and rural areas and the integration of urban and rural development. The "Key Tasks of New Urbanization Construction in 2019" clearly pointed out that it is necessary to accelerate the implementation of a new urbanization strategy with the promotion of human urbanization as the core and quality improvement as the guidance, and establish and improve the urbanization system, mechanism and policy system. -Rural integrated development, effectively promoting the free flow of urban and rural elements, equal exchange and reasonable allocation of public resources, and reshaping a new pattern of urban-rural relations. Speeding up the virtuous cycle of factors and realizing the integrated development of urban and rural areas is a top priority. [4] Therefore, studying the marketization of urban and rural factors has important practical significance for promoting the development of my country's new urbanization.

\section{Methodology}

2.1 Market-based allocation of factors- the requirement of urban-rural integrated development

It is pointed out that how to handle the relationship between industry and agriculture and between urban and rural areas well in the process of modernization determines to a certain extent the success or failure of modernization. At the Nineteenth National Congress of the Party, the deployment arrangements for the firm implementation of the strategy of Rural Revitalization were made, and the system mechanism and policy system for the integration of urban and rural development were put forward. The country leader inspected Chongqing in mid-April, 2019, and explicitly asked Chongqing to accelerate the development of urban-rural integration. He also pointed out: "Chongqing integrates big cities, big rural areas, big mountainous areas and big reservoir areas, and has a heavy task of coordinated development. Chongqing promotes high-quality development. The most arduous and arduous task is in rural areas, and the greatest potential and stamina are also in rural areas. Therefore, Chongqing must promote the rejuvenation of the rural areas and the upgrading of the cities as a whole, and strive to make the city a better place to live and the countryside a more desirable place for people." Promoting the integration of urban and rural areas is not only a major political task assigned by country leader, but also a key starting point for solving major social contradictions in the new era, and a powerful driving force for expanding development space, which has great and far-reaching significance. [5] The development potential of new urbanization comes from the growth effect of urbanization scale and the optimization effect of urbanization quality. Therefore, it is urgent to break the shortcomings of the system and mechanism, provide more effective institutional supply, and accelerate the formation of a new type of workers-peasants-urban-rural relationship with mutual promotion between workers and peasants, urban-rural complementarity, comprehensive integration and common prosperity. The Opinions on Establishing and Perfecting the System, Mechanism and Policy System of Urban-rural Integration Development (hereinafter referred to as Opinions) issued by the CPC Central Committee and the State Council is aimed at the existing obstacles of these systems and mechanisms, and puts forward a package of reform proposals on "people, land and money". [6]In a manner of speaking, the marketization of urban and rural factors is the fundamental way to break the dual structure of urban and rural areas. Under the background of building a well-off society in an all-round way, to adapt to the rapid development of digital economy and intelligent economy, it is particularly important to establish an efficient, fair, free and orderly flow of elements between urban and rural areas. [7]

2.2The role of market-oriented allocation of factors in the unbalanced development of urban and rural areas 
In some areas of China, a large number of rural people, goods and materials flow to cities unidirectionally, which requires the rational allocation of urban and rural factors, the government to play an active guiding role, and the establishment and improvement of urban-rural integration development system and policy system, that is, the key point of promoting the rational allocation of urban and rural factors is to realize the rational flow of population, land and capital between urban and rural areas, so as to gradually realize the equalization of basic rights and interests of urban and rural residents, the equalization of urban and rural public services, the equalization of urban and rural residents' income, the rationalization of urban and rural factor allocation and the integration of urban and rural industrial development. Promoting the integration of urban and rural factors helps to realize the revitalization of rural areas and avoid inappropriate government actions, resulting in the mismatch of resources.

The key problem to solve the development of new urbanization is the marketization of urban and rural elements. Market-oriented allocation of factors is a key basic reform and an innovation to truly break through the institutional mechanism that hinders the free flow of factors and realize the optimization of resource allocation. In the context of the development of new urbanization, in order to realize the market-oriented reform, market-oriented allocation of land elements, labor elements and capital elements should be promoted in a down-to-earth manner, and market-oriented allocation of technology elements and data elements should be considered. Specific measures to improve market-oriented allocation should be put forward according to different factor attributes, differences in market-oriented degree and needs of economic and social development. The market-oriented reform of factor price should be deepened, the operational mechanism of factor market should be perfected, the optimal allocation of regional, urban and rural factors should be promoted, and the guarantee of factors of independent and controllable modern industrial system should be strengthened. At the same time, the implementation guarantee of perfecting the market-oriented allocation system and mechanism of factors is put forward, including strengthening organization and leadership, carrying out pilot demonstration and creating a good environment. [8]

\section{Results and Discussion}

\subsection{Results}

In some regions of China, due to the lack of vitality in regional economic growth, the still obvious gap between urban and rural areas, the lack of linkage in the development of urban and rural industrial factors, the insufficient interactive development, the uncoordinated flow between urban and rural areas, and the incomplete orderly interaction of various factors, the rural development is relatively slow and the urban and rural development is unbalanced. Urban and rural factors refer to the main factors that affect the economic development of cities and villages, including capital, technology, information, materials, labor and other production factors. The interaction between urban and rural factors refers to the process of exchange, transmission and integration of capital and other factors in urban and rural economic development space, thus realizing the optimal allocation of resources and finally realizing the sustainable development of urban and rural areas. Without the interaction between urban and rural factors in the development of urban and rural economy, it is difficult to provide or configure reasonable resources for economic development, then the economic development will stagnate, let alone the coordinated development of urban and rural areas. Thus it is clear that the coordinated development of villages promotes the interaction of factors. Orderly interaction of various production factors between urban and rural areas is a prerequisite for coordinated development of urban and rural areas, and coordinated development of urban and rural areas has created a broad flow space for interaction of urban and rural factors. [5]

At present, there are several outstanding problems in the market-oriented flow of urban and rural elements in China's new urbanization. First, there are barriers to market entry for collectively-operated construction land. Second, the overall efficiency of the human resources market is not high. Third, the regional equity trading market is underdeveloped. Fourth, there is a lack of layout to build a batch of high-quality innovation carriers. Fifth, the overall planning of data is weak and the enthusiasm for sharing is not high. The development of new urbanization is an innovative development process, so it is necessary to solve the mismatch of elements and resources, and explore the path of free flow of urban and rural elements to promote the new development pattern. [9]

ISSN: 0010-8189 


\subsection{Discussion}

Comprehensive treatment is needed to solve the above problems. At the Fifth Plenary Session of the 19th CPC Central Committee, it was pointed out that one of the main goals of China's economic and social development during the 14th Five-Year Plan period was to make great progress in the reform of property rights system and the market-oriented allocation of factors. The market-oriented reform of factors includes the reform of land, labor, capital, technology, data and other factors. The key to improve the market allocation of factors lies in rationalizing the relationship between the government and the market, and organically combining the decisive role of the market in the allocation of resources (or factors) with the better role of the government. [10]

3.2.1 Exploring the establishment of a market entry system for rural collective construction land according to law To realize multi-subject supply of land market, it is necessary to establish a fair and reasonable value-added income distribution system for rural collective construction land entering the market. At the 12th meeting of the Standing Committee of the 13th National People's Congress of China, a vote was passed on the amendment of the Law of the People's Republic of China on Land Administration. Article 43 of the original Law on Land Administration was deleted to break down the legal barriers to the entry of rural collective construction land, which is a major institutional innovation in the Law on Land Administration. It eliminates the dual system that collective construction land cannot directly enter the market for many years, thus removing the institutional barriers for the development of urban-rural integration. The entry of collective construction land for business is the biggest highlight of the amendment to the Law on Land Administration. The procedures for land expropriation have been improved that the government should negotiate with the farmers whose land has been expropriated before the land is expropriated, and rural villagers who have settled in cities voluntarily withdraw from the homestead with compensation. However, the transaction procedures need to be clarified. [11-13]

\subsubsection{Building a unified and standardized human resources market}

The informatization level of personnel file management service should be improved to promote the high-quality development of human resource service industry. The cultivation and efficiency of human resources market is an important symbol to measure the level of economic and social development in a region. Planning and building the human resources market is the actual need of labor cooperation. Taking the construction of human resources market as the starting point, the department can play a better role as a bridge of labor cooperation platform. To solve this structural contradiction of mismatch between supply and demand, on the one hand, it is necessary to vigorously carry out employment guidance and vocational skills training for workers; on the other hand, it is necessary to extensively open up, collect and screen a large number of employment posts to create more employment opportunities for urban and rural workers. Planning and building a fixed human resources market and building a platform and carrier for market-oriented employment between supply and demand sides can effectively alleviate the contradiction of local employment difficulties, meet the needs of industrial structure optimization and upgrading for human resources development and allocation, give full play to the decisive role of the market in human resources allocation, and help to establish a unified, open and competitive employment environment, promote human resources mobility and employment and entrepreneurship, ease labor supply contradictions and structural contradictions, and provide professional, normalized and standardized high-quality and efficient human resources services.

\subsubsection{Regional equity market to be stronger and better}

Its connection with Shanghai and Shenzhen Exchange and National Stock Exchange should be promoted to guide more SMEs to be listed and displayed. Regional equity trading market is an integral part of China's multi-level capital market and an important part of encouraging scientific and technological innovation, activating private capital and supporting the real economy. At present, most enterprises in China cannot obtain development funds by means of equity transfer, and the development of OTC market, especially the regional equity market that serves as its basis, is of great significance to the development of Chinese capital market and unlisted enterprises. Therefore, regional equity trading markets that serve as the fundamental level of the capital market during the development of

ISSN: 0010-8189 
the Chinese capital market will guide capital into the grassroots that underpin the social economy and optimize capital's resource allocation in the social economy. It is suggested to realize the marketization of financial funds through the regional equity market, establish a perfect transfer system, and promote the equity pledge business. [14]

3.2.4 Promoting industrial transformation and upgrading with scientific and technological innovation Comprehensive national science center should be moderately established to promote the establishment of comprehensive industrial science and technology innovation centers in regions and guide key cities to lay out professional science and technology innovation bases. Efforts should be made to implement the national major scientific and technology facilities and support the construction of major platforms for innovations. Innovation is the first driving force to lead development. Therefore, a market-oriented and enterprise-oriented scientific and technological innovation system with the combination of production, study and research should be established to guide enterprises to establish long-term cooperative relationship with universities and scientific research institutions, vigorously research and develop new technologies, new products and new processes, and help traditional composite material enterprises to transform and upgrade.

3.2.5 Establishing an integrated big data sharing and exchange system

As a new factor of production, data elements have become "oil" in the era of digital economy. The marketization of data elements points out the way forward for further mining data resources and playing the role of data. Since the marketization of data elements in China is still in its initial stage and the non-marketization is quite serious, it is necessary to make the data resources truly an important strategic resource for China to participate in a new round of international competition by strengthening the data legislation, opening up government data resources in an orderly manner, maintaining the operational order of the data element market, cultivating and strengthening the data resource application service industry, etc. [15]

Data collection and integration should be accelerated, a multi-party collaborative data governance platform should be set up, and a comprehensive basic database should be built. With the rapid development of new generation of information technology represented by large data and artificial intelligence, digital economy has become an important engine leading global economic and social change and promoting high-quality development of China's economy. Through the technology of resource information sharing and exchange, the cross platform, cross application, cross system and cross regional resource data interconnection and resource information sharing of e-government system are realized, providing effective basic platform support for the data resource services of governments at all levels. [16] The construction of regional integrated large data center should be pushed forward. All departments are encouraged to open application scenarios and data to speed up the construction of digital government, so as to interconnect, integrate and share information and make efficient use of it, which poses many severe challenges to the informatization construction of Chinese government departments.

\section{Conclusion}

A sound market system is the prerequisite for a better market-oriented allocation. [17] The marketization of factors is an important subject to achieve high-quality development of new urbanization. However, the relatively lagging development of factor market, distorted feature allocation, insufficient contribution of total factor productivity to economic growth, and the excessive dependence of economic growth mode on the increase of input amount of factors in China at present have not met the requirements of high-quality development of new urbanization. At present, China is facing the problem of breaking down the system and institutional obstacles that hinder the free flow of factors. The development of new urbanization depends on the independent flow, efficient and fair allocation of factor markets; market-oriented allocation of factors is the development and core issue of new urbanization; the market plays a decisive role in the allocation of factor resources. Therefore, the market-oriented reform of factors is the key to the high-quality development of the new urbanization in our country at present and in the future, which requires the government to correctly play a role in the allocation of factor marketization and speed up the removal of the obstacles to the system and mechanism of the flow of elements.

ISSN: 0010-8189 


\section{Acknowledgments}

This paper was financially supported by National Social Science Foundation of China "Macro-control Policies to Promote Regional Coordinated Development" (Project No.: 14BJL080).

\section{REFERENCES}

[1] Y. L. Shi, Bringing the role of new urbanization into full play. Smart China. 2019 (04), 78-81.

[2] Learning the report of the 19th National Congress and implementing the strategy of Rural Revitalization Economic Herald. 2018 (02), 60-61.

[3] Editorial Department of this journal. Quick reading of the State Council Government Work Report 2021. Pioneer. 2021 (03), 23-24.

[4] Opinions on establishing and improving the system, mechanism and policy system of urban-rural integration and development. China Rural Science \& Technology, 2019 (12), 27.

[5] J. Y. Liu, C. Guo, Accelerating the benign cycle of factors to achieve urban-rural integration and development, The Masses. 2019 (12), 26-72.

[6] W. M. Liu, Fair and effective allocation of factor resources for promoting urban-rural integration and development. China Construction News, 2019-05-14 (006).

[7] S. H. Zhang, Synergy mechanism and reform path of market-oriented allocation of urban and rural factors. Academic Journal of Zhongzhou. 2020 (11), 70-76.

[8] Opinions on the implementation of a more complete market-based allocation system and mechanism of factors. Guangxi Daily, August 18, 2020 (004).

[9] S. W. Wan, Tang Kai. Study on the path of free flow of urban and rural factors promoting the formation of new development pattern, Regional Economic Review. 2021(02), 47-55.

[10] J. Y. Xu, Reflections on Promoting the Reform of Factor Market Configuration during the 14th Five-Year Plan Period, Tribune of Study. 2021(02), 112-118.

[11] R. Tan, Exploring the market-oriented Governance Structure of Land Elements in China. International Economic Review. 2021(02), 36-53+5.

[12] S. L. Li, Institutional arrangement and theoretical understanding of the reform of the market-based allocation of land elements Hunan Social Sciences. 2021 (02), 62-70.

[13] W. R. Qian, J. Y. Zhu, L. Qian, L. Y. Zheng, Exploring the Source of the Market-oriented Reform of Land Elements in Rural China. Issues in Agricultural Economy. 2021(02), 4-14.

[14] The joint subject team of Guoyuan Securities and Hefei University of Technology, Cai Yong. Research on the development, problems and reform of regional equity market in China. Financial Regulation Research, 2018 (04): 55-70. Constructing a more complete market-based allocation system of elements is a major task facing the current reform. Peng Sen. China Economic \& Trade Herald, 2020 (09).

[15] M. F. Lu, Marketization of Data Elements: Endowment Characteristics, Development Barriers and Promotion Strategies. Journal of Jinling Institute of Technology (Social Science Edition), 35 (01), 7-11, 2021.

[16] T. Wen, Implementation Plan of Power Hub of National Integrated Large Data Center Collaborative Innovation System issued by Four Departments, Large Data Center helps vigorous development of digital economy. China Economic Weekly, 2021(10), 90-91.

[17] Y. Xiao, Better market allocation can only be achieved with a sound market system. China Land, 2021 (03), 1 . 